\title{
Laparoscopic Retroperitoneal Ureterolysis and Aberrant Gonadal Vessel Ligation Using a Vessel Sealing Device in a Young Female with Ovarian Vein Syndrome
}

\author{
Dragos loan Feflea, MD \\ Oncological Institute "Prof. Dr. I. Chiricuță" Cluj-Napoca, Romania.
}

Claudiu Codoiu, MD

Fundeni Clinical Institute, Bucharest, Romania.

Jan-Thorsten Klein, MD

Urology Department, University of Ulm, Ulm, Germany.

Jens Rassweiler, MD

SLK Kliniken Heilbronn, Heilbronn, Germany.

Ali Serdar Gözen, MD

SLK Kliniken Heilbronn, Heilbronn, Germany.

E-mail: ali.goezen@slk-kliniken.de

(c) Mary Ann Liebert, Inc. DOI: 10.1089/vid.2016.0054
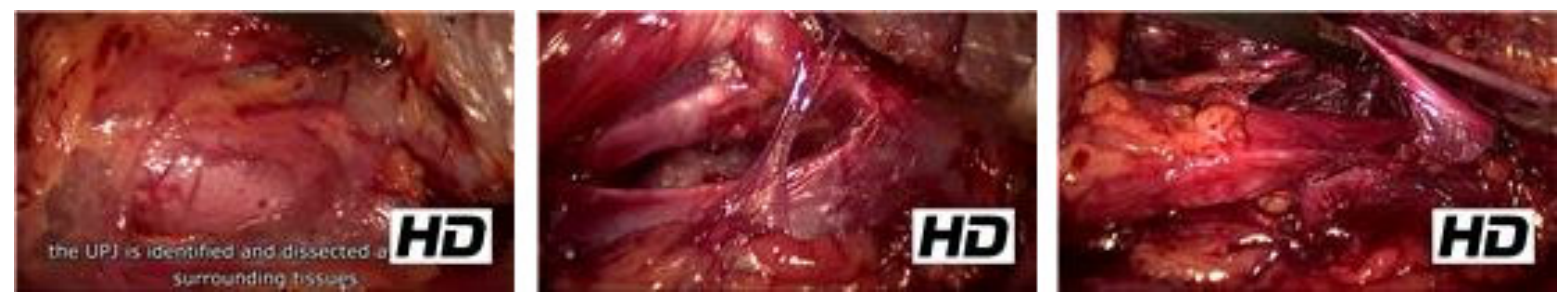

\section{Abstract}

Introduction: Ovarian vein syndrome (OVS) is a relatively rare cause for ureteropelvic junction (UPJ) obstruction, typically affecting young multiparous women. ${ }^{1,2}$ Usually, OVS causes ureteral obstruction when an aberrant or dilated gonadal vein crosses the ureter at the level of the pelvic brim. ${ }^{1,2}$ Although there are several imaging tools that can suggest an OVS as the cause for an UPJ obstruction, definite diagnosis is made through laparoscopy.

Materials and Methods: We present a case of a 24-year-old nulliparous woman with recurrent right flank pain, which was relieved after Double-J stent insertion. CT scan showed a right grade II-III

hydronephrosis. Doppler ultrasonography of kidney revealed normal findings. Retrograde pyelogram showed a stricture located on the upper third of the right ureter. A three-port diagnostic laparoscopy with retroperitoneal access was performed. After ureterolysis, an aberrant ovarian vein was identified as the cause for UPJ obstruction. Vein ligation was achieved using a bipolar vessel sealing device.

Results: Operation was effectively completed in 40 minutes with minimal blood loss. The patient was discharged on day 3 after surgery. After Double-J stent removal, at 1 month follow-up, obstruction had remitted and the patient was asymptomatic.

Conclusion: OVS is an uncommon cause for upper urinary tract obstruction in young, nulliparous women. Ligation of the dilated obstructive ovarian vein can be easily and safely achieved with the use of vessel sealing devices. Laparoscopic retroperitoneal access offers a straightforward method of both diagnosing and treating UPJ stenosis caused by vascular compression syndromes such as OVS. 
No competing financial interests exist.

Runtime of video: 4 mins 56 secs

Keywords: laparoscopy, retroperitoneoscopy, ovarian vein syndrome, surgical technique, vessel sealing

\section{Cite this video}

Dragos Ioan Feflea, Claudiu Codoiu, Jan Klein, Jens Rassweiler, Ali Serdar Gözen, Laparoscopic Retroperitoneal Ureterolysis and Aberrant Gonadal Vessel Ligation Using a Vessel Sealing

Device in a Young Female with Ovarian Vein Syndrome, Videourology. 2017, DOI: $10.1089 /$ vid.2016.0054.

\section{References}

1. Lamba R, Tanner DT, Sekhon S, McGahan JP, Corwin MT, Lall CG. Multidetector CT of vascular compression syndromes in the abdomen and pelvis. Radiographics. 2014;34:93-115.

2. Bhutta HY, Walsh SR, Tang TY, Walsh CA, Clarke JM. Ovarian vein syndrome: A review. Int J Surg 2009;7:516-520.

Original Publication Date: 2017 